\title{
Creating a digital twin of an agricultural machine
}

\author{
Kirill Nemtinov ${ }^{1, *}$, Maria Eruslanova ${ }^{1}$, Alexander Zazulya ${ }^{1}$, Yulia Nemtinova $^{1,2}$, and \\ Haider Sabah Salih ${ }^{3}$ \\ ${ }^{1}$ Tambov State Technical University, 392000, Sovetskaya st., 106, Tambov, Russia \\ ${ }^{2}$ Tambov State University named after G.R. Derzhavin, 392000, Internatsionalnaya st., 33, Tambov, \\ Russia \\ ${ }^{3}$ Department of Information Technology, Ministry of Higher Education and Scientific Research of \\ Iraq, 52nd Street, PO Box 258, Baghdad, Iraq
}

\begin{abstract}
In this paper, the authors developed an approach to creating a digital twin or an electronic model of complex agricultural machinery and proposed its structure as a set of frames. It is represented by a tuple that includes: a frame describing structural composition of the technical system under consideration; a frame describing the properties that characterize it as a whole; a set of ways to determine its properties; a set of attributive characteristics; a set of parametric graphic models of elements and a set of two-dimensional drawings. Examples of digital twins of agricultural machinery are given: a combined unit for soil preparation and sowing of grain crops and a unit for cleaning and calibration of grain seeds.
\end{abstract}

\section{Introduction}

Currently, the concept of "a digital twin" or "an electronic model of a product" is actively used in various industries. A digital twin is a collection of electronic documents describing a product, its creation and maintenance. In 2006, the Russian Federation adopted GOST 2.052-2006 "Unified system for design documentation. Electronic model of product", which considers the issues related to representation of a digital twin in a computer environment, i.e. an electronic model of a product (EMP) in the form of data set which determine not only dimensions of the product, but other properties required for its manufacture, control, acceptance, assembly, operation, repair and disposal. An EMP can be applied for:

- interpretation of the entire data set constituting the model (or part of it) in automated systems;

- visual display of product design in the course of design work, production and other operations;

- preparation of drawing and design documentation in electronic and/or paper form.

When describing all data used in solving the problem of decision-making for automated design of agricultural machinery, as well as during its operation, the set of all data should be described by its electronic model and a set of decision support models [1-5].

\footnotetext{
*Corresponding author: nemtinov@mail.gaps.tstu.ru
} 
In this regard, the paper considers the issues related to formalization of the structure and the description of individual elements of a digital twin of a technical object (product) on the example of agricultural machinery used in preparation of seeds and sowing.

\section{Structure of a digital twin for agricultural machinery}

For many tasks solved at different stages of product life cycle, a structured database is required. Data structure in an electronic model of a technical system (TS) - TS ${ }_{e m}$, describing the entire set of data is presented as follows:

$$
T S_{e m}=\left\{S c_{e m}, P_{e m}, M s_{e m}, M a_{e m}, M g_{e m}, D_{e m}\right\},
$$

where $S c_{e m}$ - structural composition frame of a TS; $P_{e m}$ - frame describing properties characterizing TS as a whole; $M s_{e m}$ - set of ways to define TS properties; $M a_{e m}$ - set of TS attributive characteristics; $M g_{e m}$ - set of parametric graphic models of a TS; $D_{e m}$ set of two-dimensional drawings of a TS. An individual property of a TS is described as follows:

$$
p_{e m, i}=\left\{n s_{e m, i}, m s_{e m, i}\right\}, i=\overline{1, N_{e m}}
$$

where $n s_{e m, i}$ - property slot name, $m s_{e m, i}$ - its value (graphic model or drawing). Elements of the set $M s_{e m}$ are: $M s_{e m}=\{$ "set by the decision maker", "chosen by the decision maker from the list", "calculated with the model", "graphic modeling", "production drawing" \}. A separate $u$-th node (detail) is described similarly to the description of the entire TS:

$$
T S_{e m}^{u}=\left\{S c_{e m}^{u}, P_{e m}^{u}, M s_{e m}^{u}, M a_{e m}^{u}, M g_{e m}^{u}, D u_{e m}^{u}\right\}, u \in U
$$

At the conceptual design phase, a structural model of a TS is used. At the same time, the following tasks are highlighted: determination of the set of functional elements (nodes) of the designed TS, determination of nodes types, their number and relative position [6-11]. Further, in accordance with the TS structural division, all internal elements of the TS are similarly described. The structural model can be presented in the form of the following tuple [12-13]:

$$
M_{\mathrm{pk}}=<U, \operatorname{Pr}>,
$$

where $U$ - set of TS functional elements (nodes) out of which it is necessary to select the subsets of possible elements (nodes) of the designed TS; $\mathrm{Pr}$ - set of rules that determine the presence and the number of functional elements in the system.

Using the TS structural model $M_{\mathrm{pk}}$ it is possible to select those nodes of the designed TS that are necessary to perform its functions from the whole set of nodes as well as to choose the type of each element.

\section{Information and logical model}

The structural model is based on the "and-or" decision tree [14-16], which displays the functional relationship between the set of TS functional elements (nodes).

To search the optimal structure of the nodes of the designed system that meets consumer requirements, it is necessary to have a set of rules that can be divided into groups: 
1) rules which allow to form a set of technological processes implemented by agricultural machinery;

2) rules which allow to determine the presence of a node in the designed TS. These rules will allow to search through "and" nodes and generate the TS structure;

3 ) rules which allow to determine the type of node included in the TS. These rules will allow to search through "or" nodes.

As an example, let us consider a number of rules with the help of which it is possible to form a set of technological processes implemented in a TS of the considered class. Production rules that make up the model are built according to the type: if ... (conditions are met), then ... (implementation of consequences).

Currently, the base contains more than 200 rules, with the help of which the optimal structural diagram of agricultural machinery can be formed. As an example, let us consider a number of unformalized rules for a combined unit that used for soil preparation and sowing of grain crops.

Specific type of rules is considered using the following examples:

a) rules for choosing the width of the cultivated soil:

- if ("traction class of the tractor" $>=0.2$ and "traction class of the tractor" $<=1.4$ ), then "working width of the cultivated soil" <=4200;

- if ("traction class of the tractor" $>=2$ and "traction class of the tractor" $<=4$ ), then "working width of the cultivated soil" $<=12600$;

- if ("traction class of the tractor" $>=5$ and "traction class of the tractor" $<=8$ ), then "working width of the cultivated soil" <=18000;

b) rules for choosing the type of frame:

- if ("working width of the cultivated soil" <=4200), then "frame" = "solid";

- if ("the width of the cultivated soil"> 4200 and "width of the cultivated soil" $<=$ 12600), then "frame" = "single-throw with folding wings";

- if ("working width of the cultivated soil"> = 12600), then "frame" = "double-throw with folding wings";

c) rules for choosing the type of tanker:

- if "frame" = "solid", then " tanker type" = "general";

- if "frame" = "solid", then "tanker type" = "separate for 2 seeding devices";

- if "frame" = "solid", then "tanker type" = "separate for 4 seeding devices";

- if "frame" = "single-throw with folding wings", then "tanker type" = "general";

- if "frame" = "double-throw with folding wings", then "tanker type" = "general";

d) rules for choosing a metering unit and a transporting unit:

- if ("frame" = "solid" and "tanker type" = "general"), then "metering unit" = "fluted roller, quantity $=1 "$;

- if ("frame" = "solid" and "tanker type" = "separate for 2 metering devices"), then "metering unit" = "fluted roller, quantity = 2";

- if ("frame" = "solid" and "tanker type" = "separate for 4 seeding units"), then "metering unit" = "fluted roller, quantity $=4 "$;

- if ("frame" = "solid" and "tanker type" = "general" and "metering unit" = "fluted roller, quantity = 1"), then "transporting unit" = "auger";

- if ("frame" = "solid" and "tanker type" = "general" and "metering unit" = "fluted roller, quantity =1"), then "transporting unit" = "pneumatic";

- if ("frame" = "solid" and "tanker type" = "general" and "metering unit" = "fluted roller, quantity = 1"), then "transporting unit" = "elevator bucket";

- if ("frame" = "solid" and "tanker type" = "general" and "metering unit" = "fluted roller, quantity $=1 ")$, then "transporting unit" = "elevator belt"; 
- if "frame" = "single-throw with folding wings" and "tanker type" = "general" and "metering unit" = "fluted roller, qty = 1"), then "transporting unit" = "pneumatic, quantity $=1 "$;

- if "frame" = "double-throw with folding wings" and "tanker type" = "general" and "metering unit" = "fluted roller, quantity = 1"), then "transporting unit" = "pneumatic, quantity = 2";

e) rules for choosing a cultipacking unit type:

- if ("frame" = "solid" and "soil type" = "black soil"), then "cultipacking unit" = "single-row ring-spur rollers";

- if ("frame" = "solid" and "soil type" = "black soil"), then "cultipacking unit" = "double-row ring-spur rollers";

- if ("frame" = "solid" and "soil type" = "black soil"), then "cultipacking unit" = "bar drum";

- if ("frame" = "solid" and "type of soil" = "black soil"), then "cultipacking unit" = "slatted roller";

- if ("frame" = "solid" and "soil type" = "black soil"), then "cultipacking unit" = "roller with a rubberized rim";

- if ("frame" = "solid" and "type of soil" = "black soil"), then "cultipacking unit" = "roller with a rigid rim";

- if ("frame" = "single-throw with folding wings" and "soil type" = "black soil"), then "cultipacking unit" = "roller with a rubberized rim";

- if ("frame" = "single-throw with folding wings" and "soil type" = "black soil"), then "cultipacking unit" = "roller with a rubberized rim";

- if ("frame" = "single-throw with folding wings" and "soil type" = "black soil"), then "cultipacking unit" = "bar drum";

- if ("frame" = "double-throw with folding wings" and "soil type" = "black earth"), then "cultipacking unit" = "roller with a rubberized rim";

- if ("frame" = "solid" and "soil type" = "loam"), then "cultipacking unit" = "singlerow ring-spur rollers" (heavy weight, soil sticking);

f) rules for choosing seeding unit type:

- if ("seed" = "cereals, wheat" and "soil type" = "black soil" and "frame" = "solid" and "tillage technology" = "minimal"), then "seeding unit" = "duck-foot weeder with a distributor";

- if ("seed" = "cereals, wheat" and "soil type" = "black soil" and "frame" = "solid" and "tillage technology" = "classic"), then "seeding unit" = "duck-foot weeder with a distributor";

- if ("seed" = "grain, wheat" and "soil type" = "black soil" and "frame" = "solid" and ("tractor with traction class" $>=0.2$ and "tractor with traction class" $<=1.4$ ) and "tillage technology" = "minimal"), then "seeding unit" = "disc knives";

Geometric parametric model. To visualize graphic images of TS elements (nodes) on the example of agricultural machinery, their electronic parametric geometric models and drawings were created.

As an example of parametric geometric models, below are the models for the following simple parts:

- a rod: $S h t=F\left(L_{S h t}, l_{S h t}, S_{S h t}, d_{S h t}, d l_{S h t}\right)$ with the following parameters: $L_{S h t}-$ total length of the rod, $l_{S h t}$ - seat length, $S_{S h t}$ - size for a flat; $d_{S h t}$ - bearing journal diameter; $d 1_{\text {Sht }}$ - thread diameter;

$L_{o p r}$ - total mandrel length; $d_{o p r}$ - diameter of sharpening for the rod. Dependency between the parameters:

$L_{S h t}=L_{O p r}+120$ 


$$
\begin{aligned}
& l_{\text {Sht }}=100 ; \\
& d_{\text {Sht }}=d_{\text {Opr }}+6 ; \\
& d_{\text {Sht }}=\left\{\begin{array}{cc}
D \leq 50, & d 1_{\text {Sht }}=\mathrm{M} 12, \\
D>50, & d 1_{\text {Sht }}=\mathrm{M} 16,
\end{array}\right. \\
& S_{\text {Sht }}=\left\{\begin{array}{cc}
D \leq 50, & S_{\text {Sht }}=10, \\
D>50, & \mathrm{~S}_{\text {Sht }}=14 ;
\end{array}\right.
\end{aligned}
$$

- a nut $G_{-} S T P=F\left(D_{G_{-} S T P}, D 1_{G_{-} S T P}, L_{G_{-} S T P}, l_{G_{-} S T P}, S_{G_{-} S T P}\right)$ with the following parameters: $D_{G_{-} S T P}$ - thread diameter, $D 1_{G_{-} S T P}-$ support end diameter, $L_{G_{-} S T P}-$ total nut height, $l_{G_{-} S T P}$ - support shoulder height, $S_{G_{-} S T P}$ - turnkey size; $d_{\text {Cang }}$ - hole diameter.

Dependency between the parameters:

$$
\begin{aligned}
& G_{-} S T P=F\left(D_{G_{-} S T P}, D 1_{G_{-} S T P}, L_{G_{-} S T P}, l_{G_{-} S T P}, S_{G_{-} S T P}\right), \\
& D_{G_{-} S T P}=d l_{S h t}, \\
& D 1_{G_{-} S T P}=d_{\text {Cang }}+20, \\
& L_{G_{-} S T P}=25, \\
& l_{G_{-} S T P}=5, \\
& S_{G_{-} S T P}= \begin{cases}D \leq 50, & S_{G_{-} S T P}=19, \\
D>50, & S_{G_{-} S T P}=20 .\end{cases}
\end{aligned}
$$

Fig. 1 and Fig. 2 show geometric parametric 3D models and drawings of these parts.

\section{Results and discussion}

Fig. 3 shows visualization of an electronic geometric model of a combined unit for soil preparation and sowing of grain crops, and Fig. 4 illustrates a model of the unit for cleaning and calibration of grain crops.

The combined unit for soil preparation and sowing of grain crops provides a combination of soil preparation, sowing and soil cultipacking in one machine.

In the proposed design of the machine, protection of seeds from damage on the sieve and its high productivity during cleaning and calibration of grain crops is ensured by the following mechanisms:

- transportation of seeds for cleaning and calibration is carried out using scoops with the volume of $3 \mathrm{dm}^{3}$;

- seeds move along and pass the sieves not at the angle of $0^{\circ}$, but at $90^{\circ}$, which eliminates damage to the seeds;

- energy consumption and the number of service personnel are reduced.

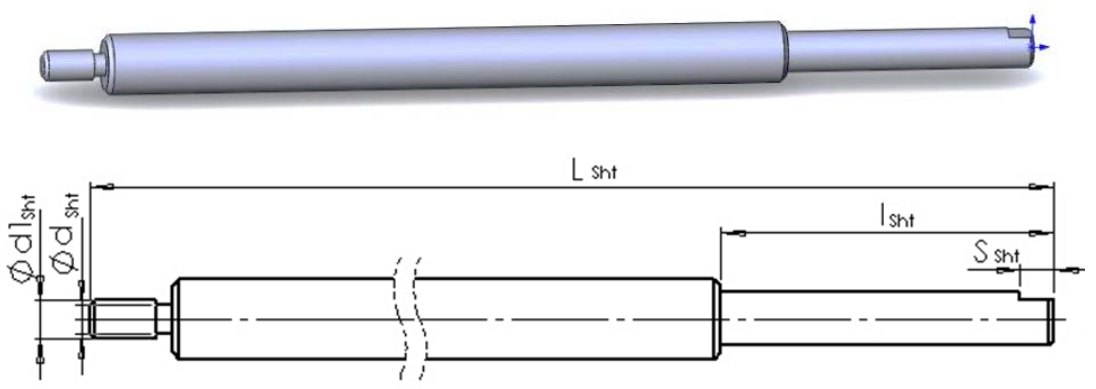

Fig. 1. Geometric parametric 3D model and drawing of a «rod» 

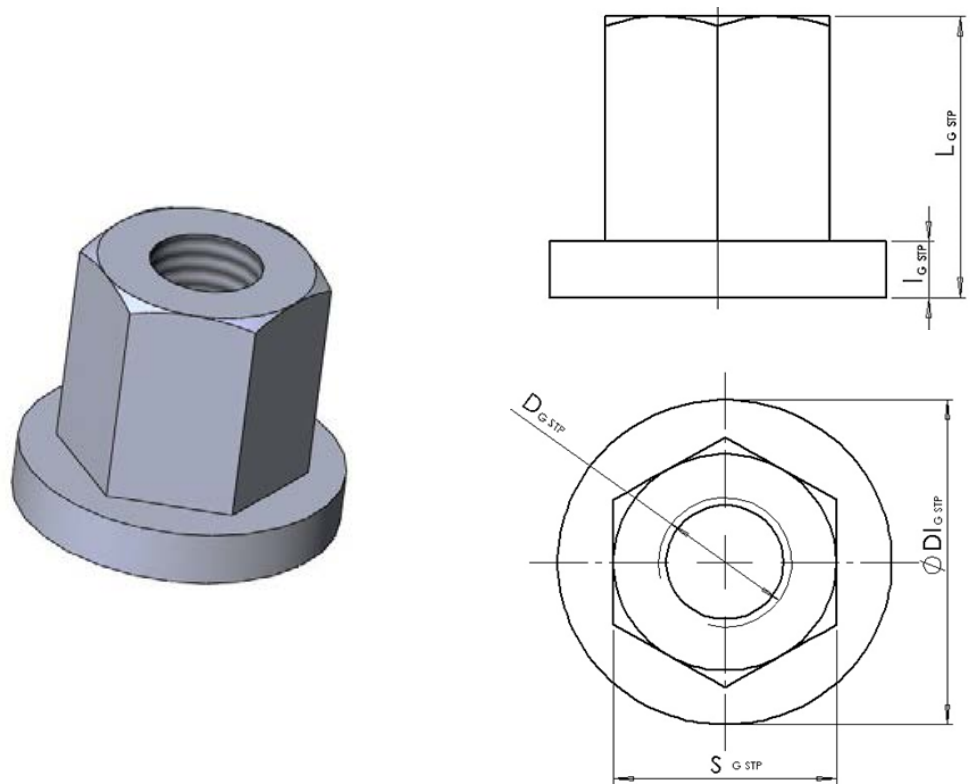

Fig. 2. Geometric parametric 3D model and drawing of a "nut"

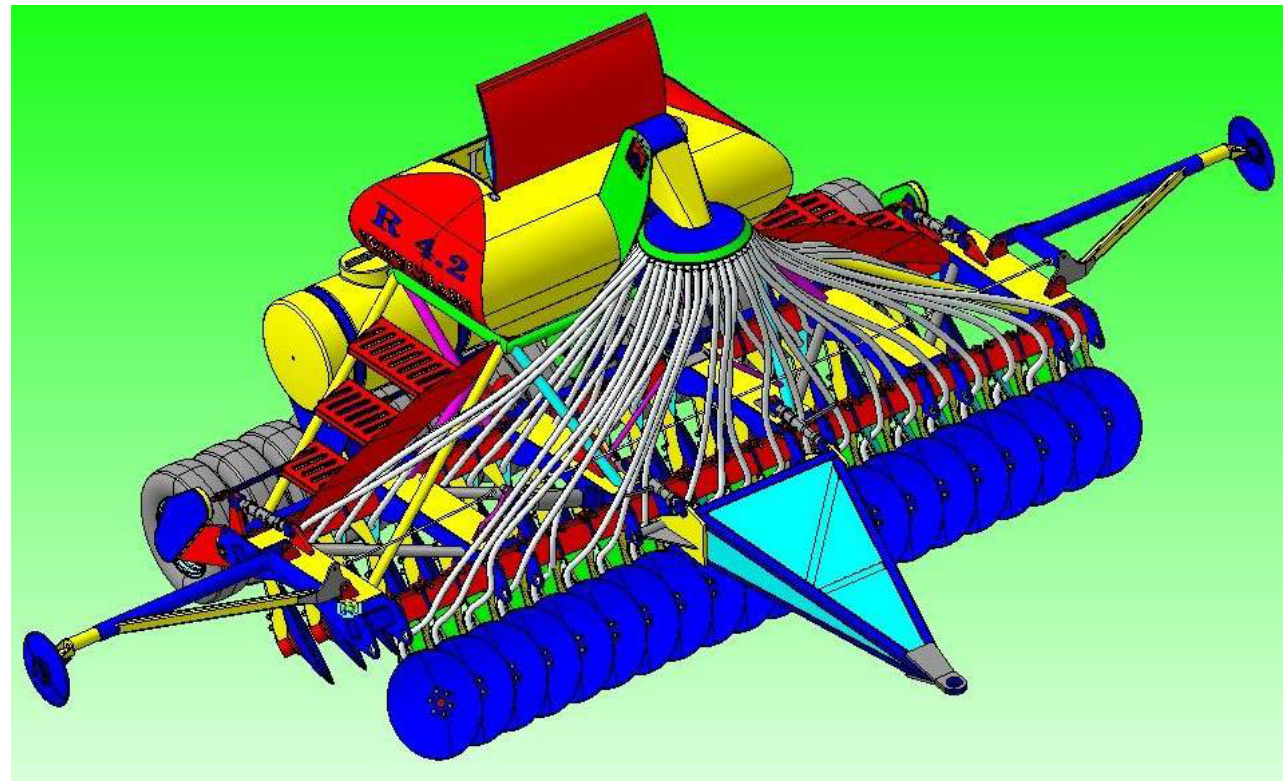

Fig. 3. Visualization of an electronic geometric model of a combined unit for soil preparation and sowing of grain crops

When developing the electronic geometric model of agricultural machinery, the authors used 2D-3D drawing systems (KOMPAS and AutoCAD). Mechanical calculations for these units were performed in accordance with Russian GOST 23738-85. At the same time, the 
authors used MathCad system, which allows automating the procedure for their implementation.

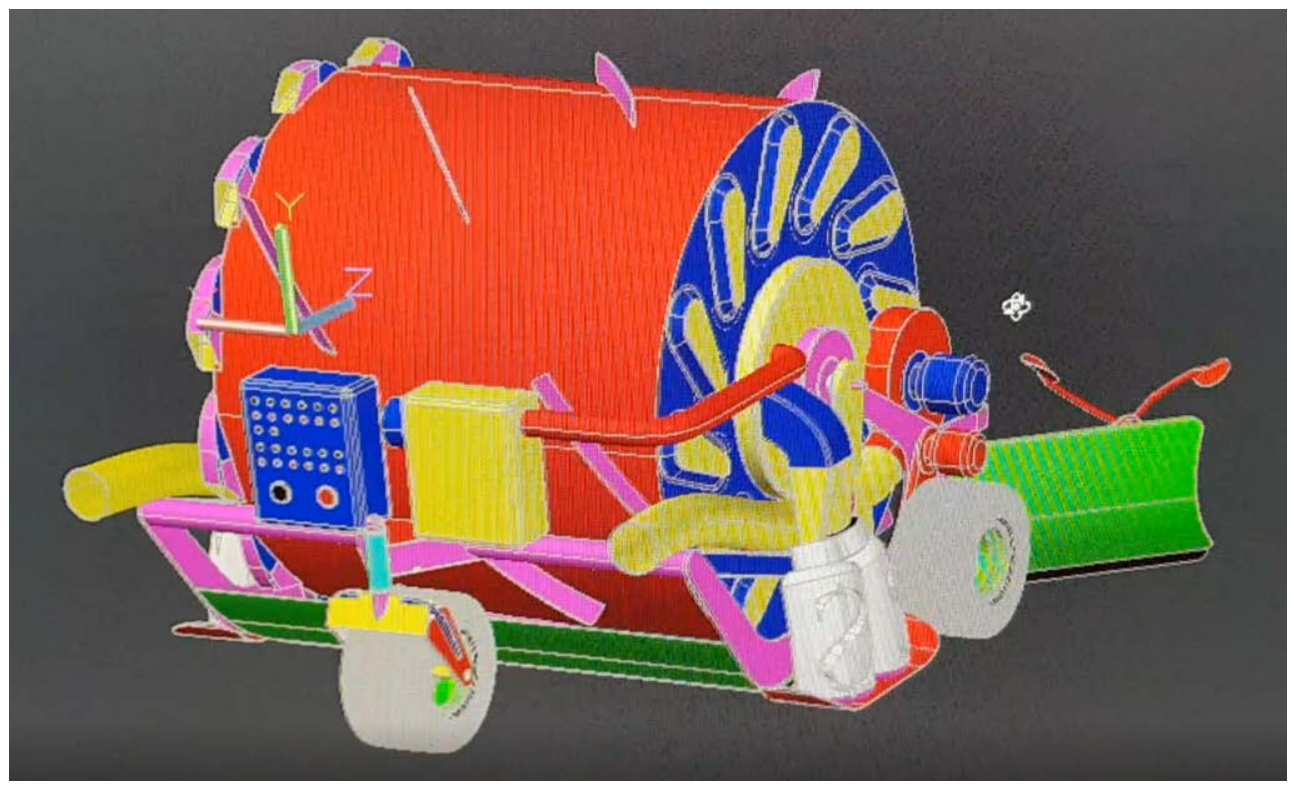

Fig. 4. Visualization of the model of the unit for cleaning and calibration of grain seeds

\section{Conclusion}

In this paper, the authors developed an approach to creating a digital twin of a technical system using the example of agricultural machinery, which includes combined units that implement the stages of seed preparation and sowing. The digital twin model is presented in the form of a hierarchical frame structure that includes parametric three-dimensional geometric models and drawings of separate units, devices, mechanisms and parts, as well as their attributive data. The proposed formalization of the digital twin was tested on a number of design projects for agricultural machinery implemented by OOO «KB ERUSLAN» (Russia) and Tambov State Technical University.

\section{References}

1. V.A. Nemtinov, Yu.V. Nemtinova. Journal of Computer and Systems Sciences International. 44(3), 389-398 (2005)

2. V.G. Mokrozub, V.A. Nemtinov A.V. Mokrozub. Chemical and Petroleum Engineering. 53(5-6), 326-331 (2017)

3. L. Lijing. Transactions of the Chinese Society of Agricultural Engineering. 31(11), 40$45(2015)$

4. V.G. Mokrozub, V.A. Nemtinov. Chemical and petroleum engineering. 51(7-8), 31-35 (2015)

5. G.V. Prasanna Kumar, B. Srivastava, D.S. Nagesh. Computers and Electronics in Agriculture. 65(1), 26-35 (2009)

6. J.M. Wang, L. Zhang, Y.B. Liu, X.N. Mo, G.Q. Ren. Computer Integrated Manufacturing Systems. 16(10), 2017-2023 (2010) 
7. V.G. Mokrozub, K.D. Manuilov, V.V. Gorshkov, T.S. Gorshkova. Chemical and Petroleum Engineering. 51(9-10), 613- 617 (2016)

8. A.B. Borisenko, S.V Karpushkin. Journal of Computer and Systems Sciences International. 53(3), 410-419 (2014)

9. A. Ivannikov, V. Kulagin, A. Romanov, B. Pozdneev. EWDTS-2016 Proceedings, 14th IEEE EAST-WEST DESIGN \& TEST SYMPOSIUM (2016)

10. V. Nemtinov, A. Zazulya, V. Kapustin, Y. Nemtinova. Journal of Physics: Conference Series. 1278(1), 012018 (2019)

11. V. Vamerali, M. Bertocco, L. Sartori. Soil \& Tillage Research, 89(2), 196-209 (2006)

12. L. Yang, X.T. He, T. Cui, D.X. Zhang, S. Shi, R. Zhang. International Journal of Agricultural and Biological Engineering. 4, 1-9 (2015)

13. T. Zhao, Y. Zhao, T. Higashi, M. Komatsuzaki. Engineering in Agriculture, Environment and Food. 5(2), 50-56 (2012)

14. V. Nemtinov, N. Kryuchin, A. Kryuchin, Y. Nemtinova. E3S Web of conferences. 126, 00003 (2019)

15. K. Nemtinov, A.Eruslanov, Y. Nemtinova. E3S Web of Conferences. 126, 00003 (2019)

16. V. Nemtinov, V. Sergeev V. and Yu. Nemtinova. IOP Conf. Series: Materials Science and Engineering. 709, 033072 (2020) 